\title{
METHODS OF ANALYSIS AND ESTIMATION OF RISKS AT THE ENTERPRISES OF NON-FINANCIAL SPHERE OF LATVIA
}

\author{
Irina Voronova \\ Riga Technical University, 1 Kalku St., LV-1658 Riga, Latvia. \\ E-mail: irina.voronova@rtu.lv \\ Received 5 May 2007; accepted 15 October 2008
}

\begin{abstract}
The author considers the problems of analysis and assessment of risks at the enterprises of non-financial sphere basing on tactical standards of risk management. The author studies the development and impact of the theory of economic cycles on the system of risks in entrepreneurship of Chizhevsky's and Kondratjev's temporary cycles that are at the same time space cycles. The author expresses their attitude to the opportunity of using autogenetic and risks identification. Astrolinguistics studies the nature of changes in macroeconomic environment on the basis of information about the mutual position of the solar system's planets in the process of their motion. This paper discusses how variety of scope methods may be applied for assessment of the profile of risks at the enterprise.
\end{abstract}

Keywords: risk, risk management, non-traditional methods, economic cycles, astrolinguistics, tests, risk score.

\section{Introduction}

Under the influence of different factors entrepreneurial activities may be misbalanced and terminated at all. That is why risk problem is crucial for all enterprises regardless of their scope and branches. Unlike financial sector of economy non-financial sector lacks strict requirements on organization for risk management. The conducted research in the field of risk management in large international companies, for instance, the study of Ernst \& Young (Independent Directors...2007) allows to conclude that during the recent 2-3 years the levels of business risks have substantially increased. This fact was mentioned by $72 \%$ out of 150 respondents. The respondents mainly considered dangers concerned with the environment in which the activity of the company was conducted (17\%), operational risks (12\%), technological risk (11\%) and competition (10\%). What is important in risk management organization is obtaining information about internal and external environment, needed for decision-making. Taking into account the analysis of such information and management risk objectives it is possible to determine correctly the probability of occurrence of events, to find out the risk level and evaluate its cost.
In the published study of the World Bank "Doing Business in 2006: Creating Jobs" (2006) Latvia has not demonstrated the best indicators of solvency process efficiency in European in Central Asian regions. In Latvia the process of insolvency lasts on average 3.0 years, cost of bankruptcy proceeding is $13.0 \%$ and recovery rate, which calculates how many cents on the dollar claimants recover from an insolvent firm, is 34.8. Similar indicators for Lithuania are $1.7 ; 7 \%$ and 50.5 cents on the dollar. Estonia - 3.0; 9\% and 39.9 cents on the dollar (Doing Business...2006). According to the indicator "Closing Business" in the region "Europe and Central Asia" it is Lithuania which is the 1-st, Estonia - the 6-th and Latvia occupies only the 9-th place. Latvia occupies the 24-th place among all the studied 175 countries of the world in the field of winding up commercial activities (in terms of 10 criteria used for assessment), being far ahead of such states as Austria, France, Spain and Italy, but Latvia lags behind the neighbouring countries such as Lithuania (16-th place) and Estonia (17-th place). The given material testifies to the fact that the state aims at forming external environment of risk management organization. It is 
possible to gain the impression about external environment risks on the basis of ratings of country risks and business environment relying on expert assessment. These famous macro-oriented models, introducing periodic editions include: BERI (Business Environment Risk Index), WPRF (World Political Risk Forecasting), ICRG (International Country Risk Guide) and Economist Intelligence Unit. Table 1 gives the characteristic country risks on the five constituents for Estonia, Latvia and Lithuania.

Table 1. Description of Country Risk and Business Environment of Estonia, Latvia and Lithuania (on the state of 15.07.2007) (Economist Intelligence Unit 2007)

\begin{tabular}{lccc}
\hline & Estonia & Latvia & Lithuania \\
\hline Country risk summary*: & & & \\
\hline 1. Sovereign risk & $\mathrm{A}$ & $\mathrm{BBB}$ & $\mathrm{BBB}$ \\
\hline 2. Currency risk & $\mathrm{BBB}$ & $\mathrm{BB}$ & $\mathrm{BBB}$ \\
\hline 3. Banking sector risk & $\mathrm{BBB}$ & $\mathrm{BBB}$ & $\mathrm{BBB}$ \\
\hline 4. Political risk & $\mathrm{A}$ & $\mathrm{A}$ & $\mathrm{A}$ \\
\hline 5. Economic structure risk & $\mathrm{BBB}$ & $\mathrm{BBB}$ & $\mathrm{BBB}$ \\
\hline
\end{tabular}

Business environment ranking summary:

\begin{tabular}{lccc}
\hline 1. Value of index** & 7,86 & 7,12 & 7,02 \\
\hline 2. Global rank*** & 21 & 35 & 38 \\
\hline 3. Regional rank**** & 1 & $6^{* * * * *}$ & 8 \\
\hline
\end{tabular}

$\mathrm{AAA}=$ least risky; $\mathrm{D}=$ most risky; $* * 10$ maximum; $* * *$ out of $82 ; * * * *$ out of $16 ; * * * * *$ out of 17 .

In 2007 international rating agencies stated that risks in the Baltic countries increased Fitch Rating introduced as index $A$ (economic situation can affect finance) for Estonia and Lithuania, but Latvia was assessed as $A-$. Fitch holds the view that Latvia may become the most vulnerable and Lithuania least of all provided sudden adjustment of capital flow leading to a sharp slowdown of economic growth. In these conditions it is important to make active all the mechanisms conducive to strategic goals achievement, realize innovative decisions and increase competitiveness. These mechanisms include risk management.

However, there is a long way ahead to comprehension of the necessity of creating an exhaustive system of risk management both in the system of higher education and in the system of training the staff already working in industrial enterprises. At the large enterprises in Latvia for risk management either special units have been established or their management is conducted within the framework of the system of quality management (in case of getting or training for getting this quality management certificate). However, in both cases in risk management an active role belongs to the system of an internal audit (Guidance of risk...2006). Despite the current progress compared with small and medium-sized enterprises it is not worth considering that non-financial sphere of enterprises started creating a comprehensive system of risk management (Enterprise-wide risk management ERM-COSO). Risk managers are not fully aware of the fact that ERM-COSO is not only an instrument which helps reduce threats but also a mechanism for establishing an environment, improving the process of decision-making which retains and increases the value of an enterprise. At present in Latvia legislative normative demands for business risk management continue to develop and improve.

\section{Methods of risk analysis in the system of risk management in Latvia}

To deepen into the complexity of the problem of the application of methods of identification and risk analysis at the enterprises of non-financial sphere it is necessary to take into account the fact, that risk has two constituents: downside risk (threats) and upside risk (opportunities). Risk should be considered as quantitative measure of threat, as probable measure of threat, as probable measure of occurrence of technogenic or natural phenomena, as well as mathematical expectation of damage caused by accidents, catastrophes and hazardous natural phenomena.

Risk cost means possible losses of entrepreneurial costs on reduction of the value of possible losses or costs on recovering these losses and their consequences. An increasing demand for risk management encourages risk managers to carefully consider the disposition of risk at their enterprises. It is not so easy to discover and assess the range of risk at an enterprise once and for ever in the 21-st century. The range of risk changes not only after recognition of a separate kind of risk but also its composition. Changes in the risk range occur not only as a result of sudden coincidence, but also as a result of the movement of an enterprise according to its life cycle. In all cases the size of risk at an enterprise may be described with the help of the system, expressions (1)-(4):

$$
\begin{aligned}
& R_{t}=F\left(R_{e f} ; R_{e d} ; R_{\text {eind }} ; f\left(R_{\text {in }}\right)\right), \\
& R_{t c}=f\left(R_{\text {in }}\right)=f\left(R_{p i} ; R_{p f} ; R_{\text {popa }} ; f\left(R_{o}\right),\right. \\
& R_{e f}=f\left(T_{t c o}\right)=f\left(T_{p c p} ; T_{c b} ; T_{c o}\right), \\
& T_{t c o} \in T_{c g d},
\end{aligned}
$$

where $R_{t}$ - the total value of the risk at an enterprise; $R_{t c}$ - the total controlled risk at an enterprise; $R_{e f}-$ the 
value or the risk which is indicated by external factors; $R_{\text {ed }}, R_{\text {eind }}$ - risk value indicated by external direct and indirect factors; $R_{t p}$ - value of risk which is indicated by the internal factors of an enterprise; $R_{p i}, R_{p f}$ - risk value indicated by relevant processes of investment and financing at an enterprise; $R_{\text {popa }}$ - risk value indicated by the process of organization of production activity at an enterprise; $R_{0}$ - risk value indicated by other internal factors at an enterprise; $T_{c p}$ - product life cycle containing 8 directions; $T_{c b}$ - branch life cycle containing 6 directions; $T_{c o}$ - life cycle of an organization containing 7 directions; $T_{t c o}$ - total life cycle of an organization; $T_{c g d}-$ cycle of global development (Komkova, Voronova 2003).

Discovering risk factors, risks classification and their analysis, occupies an important place in entrepreneurial risk management. Risk Management is: "the culture, processes and structures that are directed towards realising potential opportunities whilst managing adverse effects" (Australian...2006). The process of risk management is regulated by tactical standards used in many countries. For example, in compliance with Australian/ New Zealand Standard AS/NZS 4360:2004 risk management process includes 8 Building Blocks: 1. Risk Management Training\&Awareness; 2. Establish the Context; 3. Identify Risks; 4. Analyse Risks; 5. Evaluate Risks; 6. Treat Risks; 7. Communicate and Consult; and 8. Monitor and Review (Australian...2006). In accordance with Risk management Standard (AIRMIC, ALARM, IRM: 2002) the process of risk management, consisting of 7 elements, will include Risk Assessment: Risk Analysis (Risk Identification, Risk Description, Risk Estimation) and Risk Evaluation (A Risk Management... 2002).

A system of risk management is a system of supporting different decision-making, aiming at reduction of the existing indefiniteness. Various methods of classification of risk assessment are available in scientific literature (A Risk Management... 2002; Order provided ...2006; Main trends of assessment...2007; Pettere, Voronova 2003), but out of all the cluster of quantitative and qualitative methods there may be singled out 3 groups of methods: expert method, statistical and special coefficient methods (Fig. 1) (Order provided...2006; Main trends of assessment...2007; Pettere, Voronova 2003). Very frequent is a combination of quantitative and qualitative methods of risk assessment, in this case it is possible to speak about a semiquantitative assessment method. It is possible to distinguish the most commonly applied methods of risk assessment in the field of their application for analysis (identification, description and estimation) and com-

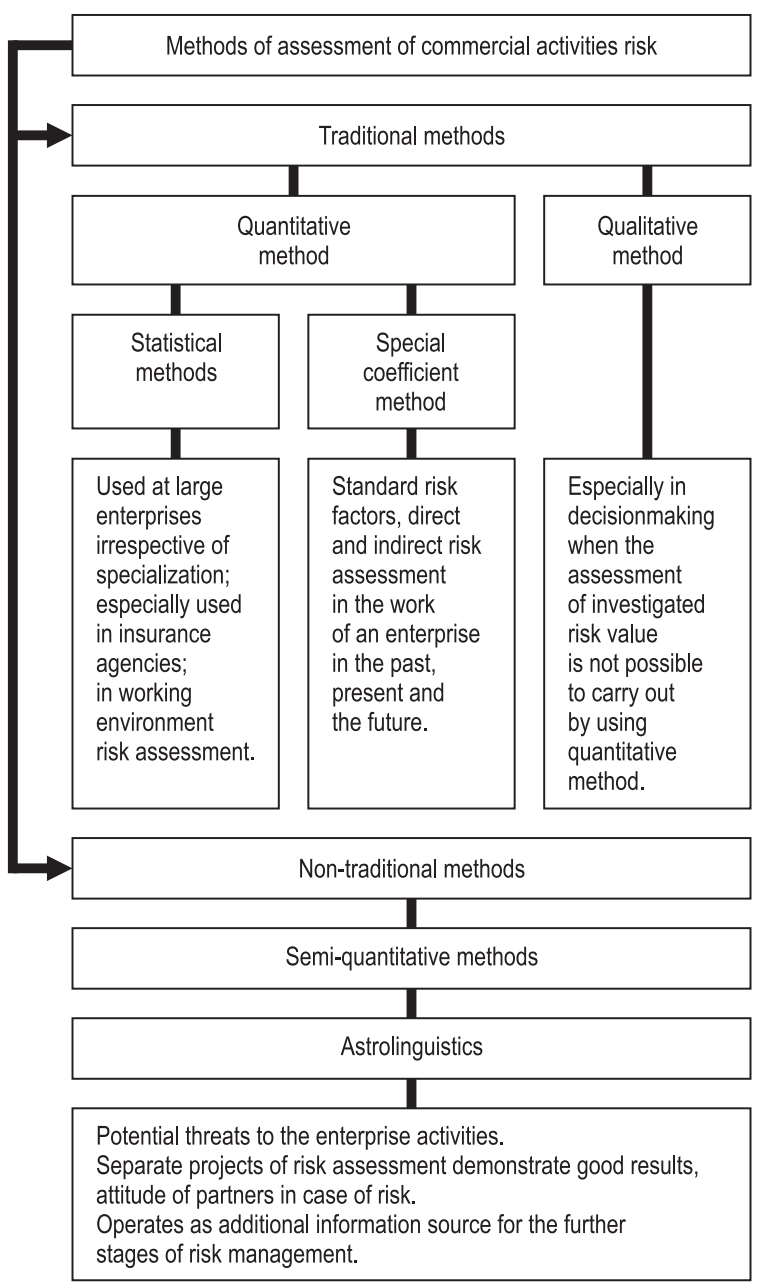

Fig. 1. Most frequently used methods of the assessment of the risk of entrepreneurial activities and spheres of their application (Pettere, Voronova 2003)

parison of different kinds of risk (risk evaluation). For example, methods of assessment of any risks: STEP/ PEST and SWOT analysis, environmental threats and opportunities matrix (ETOM), "SO-What" analysis, modelling of interrelations, event tree analysis, decision making in the risk conditions and indefiniteness, statistical inference, life cycle of various elements of an organization (length of existence, important factors), analysis of financial coefficient, scenario method. Technologies of negative risks (hazards) assessment may be exemplified by: threat analysis, a tree of errors, FMEA analysis (Failure Mode \& Effect Analysis). Methods of positive risks assessment are: methods of marketing impact, research and development, testing marketing, business effect analysis and Value at Risk. Methods of risk analysis depend on the branch of enterprise and kinds of risk. Table 2 gives examples of the methods of the analysis of industrial risk depending on the stage of the life cycle of an enterprise, having hazardous production. 
Table 2. Recommendations on the application of methods of risk analysis at different stages of life cycle of the enterprise, having hazardous production and calculate their cycle

\begin{tabular}{lcccccc}
\hline \multicolumn{1}{c}{ Method of Analysis } & \multicolumn{5}{c}{$\begin{array}{c}\text { Stages of the life cycle } \\
\text { of enterprise }\end{array}$} \\
\cline { 2 - 7 } & 1 & 2 & 3 & 4 & 5 \\
\hline What - If & + & ++ & +++ & +++ & ++ \\
\hline Check list & + & ++ & ++ & +++ & ++ \\
\hline $\begin{array}{l}\text { Hazard and Operability } \\
\text { Study - HAZOP }\end{array}$ & + & +++ & ++ & ++ & +++ \\
\hline $\begin{array}{l}\text { Failure Mode and } \\
\text { Operability Study }\end{array}$ & + & +++ & ++ & ++ & +++ \\
\hline $\begin{array}{l}\text { Fault Tree Analysis and } \\
\text { Event Tree Analysis }\end{array}$ & + & +++ & ++ & ++ & +++ \\
\hline $\begin{array}{l}\text { Quantitative Risk } \\
\text { Analysis }\end{array}$ & +++ & +++ & + & ++ & +++ \\
\hline Note: Stages of the life cycle & & & & & & \\
\hline
\end{tabular}

Note: Stages of the life cycle of an enterprise having hazardous production: 1) choice of location of enterprise; 2) projecting; 3) Introduction into operation; 4) exploitation; 5) reconstruction, +- least suitable method of analysis; ++- recommended method; +++- the most suitable method.

The methods of assessment of working environment risks, recommended for application at the enterprises of Latvia are stated in detail in the study "Main trends of assessment of working environment risks" (Main trends of assessment...2007).

\section{The place of traditional and non-traditional methods of risk analysis in the system of risk management in Latvia}

Besides the traditional methods of identifying and assessing risk nowadays, non-traditional methods may be used as well. One of the non-traditional methods of risk identification is astrolinguistics. The author expresses her opinion in relation to risk assessment by applying such a non-traditional method as astro-linguistics (Schumpeter 1939; Zalozneva 2007). Application of different astrolinguistic methods, investigation of social-economic cycles and occurring crises in a span of time have a range of values: worked out mathematical models and instruments to observe the movement of the planets and calculate their cycle.

There is proof that the Solar system planets cycles provide an opportunity to discover changes in social and economic development trends. The latter circumstance may be used in doing SWOT analysis of large enterprises projects. Introduction of astrological methods for investigation of economic cycles and risk is aggravated by the fact, that there exist few special researches with practical application in making urgent forecast and unsatisfactory exactness. There is strong prejudice against risk assessment from the economic point of view especially by management personnel, who consider it as "rubbish".

Astrolinguistics holds the view that at a certain moment of time all the objects undergo processes which are subject to uniform rules. Astrolinguistics is based on astrologic symmetry, the principle of holographic information and genetic unity in everything. Astolinguistics means that at a certain moment of time there are activities in all objects which are subject to unified laws. These processes can be described by means of astrological symbols and operated on the basis of the principle of symmetry, which is a universal principle of construction and cognition of the world. Horoscope is an instrument in establishing correlation between space and time. Horoscope is a mathematical model which is like a circle of eclipse on which the position of the planets at a certain period of time is fixed for a given geographic place on the Earth.

Astrolinguistics does not consider laws within a year or month but in the framework of time, that corresponds to the cycles of the activity of the Sun. It was A. Chizhevsky who first discovered periodic changes in the sun activities. Later on an economist N. Kondratjev discovered economic cycles. In 1939 an American J. Schumpeter published a book "Business activities cycles" (1939) and Kondratjev's discovery became famous in the business world. Cycle theory has existed for 2.5 thousand years. Greek philosophers discussing accumulation of empiric knowledge made an attempt to describe cycles which clearly manifested and participated in the development of nature and humanity. At the beginning the cycle was demonstrated like a circle with the same movement phases. At present according to R. Mougle data since 1940 around 5000 cycle phenomena of different types have been discovered (Mougle 1995). For instance, Kutchin's cycles with a length of 3-5 years concerned with a relative value of material resources reserves at enterprises; schools of Dzagler's cycles, lasting 7-10 years appearing as a result of interaction of different credit-monetary factors; S. Kuznets' cycles with a length of around 29 years, resulting from the terms of reproduction in building. A. Chizhevsky discovered 22 and 11-year cycles of the Sun activity. The cycles discovered by N. Kondratjev (long-wave cycles) lasted 45-50 years (Jakovec, 1999; Mougle 1995; Schumpeter 1939; Risk Management...2000), sprung as a result of structural reconstruction of the technological base of public production. Theoretical conceptions of long waves are im- 
portant in the way, that they give a necessary basis for the assessment of economic situation and the forecast for the future. Every 5-6, 11, 16-17, 22, 45-67 years the waves of the Sun activity pose enterprises against a choice and the results depend on their own: whether they will be able to improve their activity (life) or will lose everything achieved in the previous years. For practical purposes it is reasonable to deal with various digital characteristics in economic cycles periodization in order to be more precise in stating risk factors coming from internal environment when entrepreneurs are planning their business activity. However, there are few practical studies on assessment of the cycle length of the development of separate enterprises. To assess risk groups by means of traditional risk investigation methods it is possible to use astrolinguistic methods, combining different methods of risk assessment, it is worth developing common strategy of risk management. To make risk management in entrepreneurship more effective it is necessary to carry out analysis of changes in nature and also analysis of social-economic changes and make a forecast by means of astrolinguistic analysis. To make a fast and qualitative astrolinguistic analysis it is necessary to work out a special computer programme, which unites astrolinguistic calculations, used by risk managers in the analysis of risk factors. Besides the assessment of technical aspects of risk, successful use of non-traditional methods, it would be reasonable to overcome the prejudice of the potential users against such astrological results.

The world practice gives plausible examples of successful application of economic astrology in economy and finance management, for instance, V. Angermeyer in his study "Economic astrology - economy and finance from the cosmological point of view". Using astrology he predicted stock exchange collapse in 1987 and economic crisis of the autumn of 1989. The author's practical experience in using astrolinguistics for the discovery of entrepreneurial risk in Latvia, testifies to the application of only separate devices of astrolinguistics mainly in the assessment of social risks, risks concerned with an individual as such, e.g. the assessment of potential of professionalism of separate employees (Budjashkina 2002; Zalozneva 2007).

\section{Discovery of the risks at the enterprises of non-financial sphere by using test system}

It is the system of financial ratios that is commonly used to identify and analyse financial risks at the enterprises of non-financial sphere. Their application in general gives good results but the length of the life cycle of an enterprise for different countries in various branches differs. However, the curve of the life cycle consisting of individual stages each of which describes the dependence of an enterprise on external and internal conditions, occurring at a certain time span, will be identical for economic subjects. Each stage has specific groups of financial risks, affecting the operation process of an enterprise. Table 3 introduces organizationaleconomic peculiarities of the operation of an enterprise at different stages of its life cycle. Fig. 2 gives an interrelation of the levels of business activity and financial risk entailing the financial risk depending on a stage. At the introductory stage an enterprise from the point of view of financial risk is more prone to the impact of external factors.

Table 3. Organizational and economic peculiarities of the functioning of an enterprise at its various life cycles

\begin{tabular}{|c|c|c|c|}
\hline 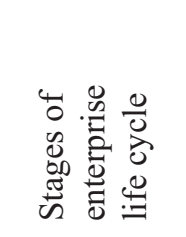 & 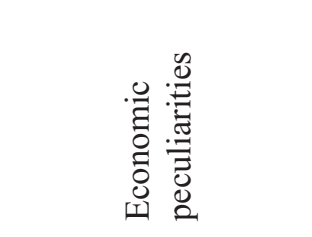 & 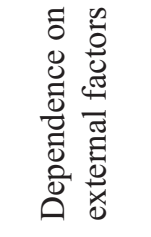 & 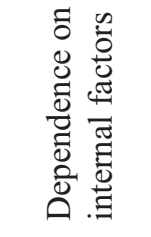 \\
\hline Introductory & $\begin{array}{l}\text { A large share of loan } \\
\text { capital, great finan- } \\
\text { cial risk, low profit- } \\
\text { ability indicators }\end{array}$ & Strong & Poor \\
\hline Growth & $\begin{array}{l}\text { Optimal financial } \\
\text { risk, high produc- } \\
\text { tion risk, high profit- } \\
\text { ability indicators }\end{array}$ & Moderate & Moderate \\
\hline Maturity & $\begin{array}{l}\text { Optimal common } \\
\text { risk, high profita- } \\
\text { bility indicators, } \\
\text { reduction of working } \\
\text { capital turnover indi- } \\
\text { cators }\end{array}$ & Poor & Strong \\
\hline Decline & $\begin{array}{l}\text { High common risk, } \\
\text { low profitability indi- } \\
\text { cators, turnover and } \\
\text { solvency indicators }\end{array}$ & Poor & Strong \\
\hline
\end{tabular}

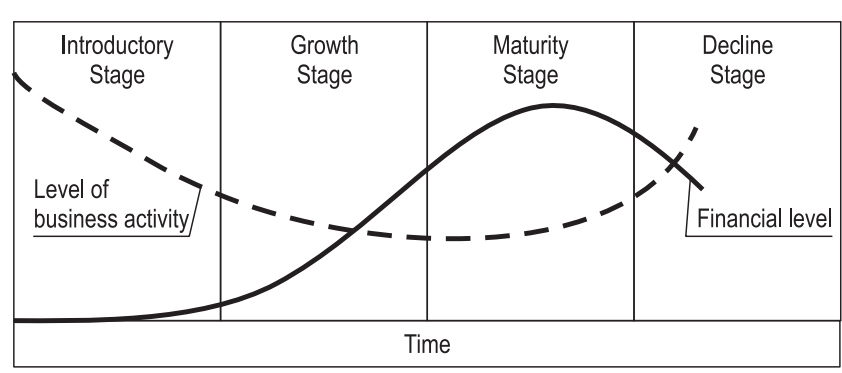

Fig. 2. Potential development of financial risk for enterprise 
Taking into account that an enterprise can control only internal factors (the first, the second... in sequence) at this stage it is needed to control a share of loan capital, profitability of main activity and liquidity indicators. However, because of instability of stability indicators at a given stage the further factors are the indicators of the efficiency of the main activity of the enterprise, volume of sales production, cost value. It is important to assess their dynamics.

Depending on the change in time of profit from sales and cost value, there will be level of financial risk. At the stage of the assessment of the risk of enterprises being at introductory stage in addition to the above -mentioned indicators it is necessary to take into consideration the condition of financial stability of an enterprise functioning. At the growth stage, a rapid increase occurs in profit and stabilization of financial indicators of relation to equity and loan capital. The profit is capital. The profit is considered as past growing dynamics of indicators. It is possible to assess the level of financial risk of an enterprise at this stage on indicators of relation to equity and loan capital. The profit is considered as fast growing, dynamics of volume of sales is positive. At the maturity stage an enterprise operates in full swing, the indicators are stable but due to increasing competition and wearing out of capital may shift to the decline stage. In this case it is necessary to control the volume of sales and the turnover of assets will testify to the reduction of competitiveness of production and increase stock. At this stage it is not possible to judge about the level of the financial risk of the enterprise according to the indicators of cost value and profits from sale, as there may take place a strategy of renovation of assets which may tell on the indicators, but not always means the increase of the financial risk of the enterprise. The occurrence of crisis can be predicted according to its probability and impact. To discover financial risk by using publicly available information more frequently methods of special coefficients are applied.

Test task. To discover the signs of the financial risk of an enterprise in the short time period, taking into account the organizational and economic features of its functioning at different stages of life cycle. General description of a test. During the test analytical relations are calculated, which characterize proper signs of financial stability at different stages if an enterprise is at different life cycles (Tables 4, 5 and 6). The au-

Table 4. Determination of level of financial risk of enterprise, being at the introduction stage

\begin{tabular}{|c|c|c|c|}
\hline \multirow[t]{3}{*}{ Level of financial risk } & \multicolumn{3}{|c|}{ Evaluation indexes } \\
\hline & \multirow{2}{*}{$\begin{array}{c}\text { Coefficient of coverage } \\
\text { of capital assets }\end{array}$} & \multicolumn{2}{|c|}{ Dynamics of indexes } \\
\hline & & Profit from realization & Cost value per unit \\
\hline 1. Minimum & $K_{c a} \geq 1$ & $P_{p}(t)=P_{p}(0)+a t$ & $I_{p}(t)=l_{p}(0)-a t$ \\
\hline 2. Middle & $K_{c a} \geq 1$ & $P_{p}(t)=P_{p}(0)+a t$ & $I_{p}(t)=l_{p}(0)+a t$ \\
\hline 3. High & $K_{c a} \leq 1$ & $P_{p}(t)=P_{p}(0)-a t$ & $I_{p}(t)=l_{p}(0)-a t$ \\
\hline 4. Situation of appearance of financial risk & $K_{c a}<1$ & $P_{p}(t)=P_{p}(0)-a t$ & $I_{p}(t)=l_{p}(0)+a t$ \\
\hline
\end{tabular}

Table 5. Determination of level of financial risk of enterprise, being at the growth stage

Level of financial risk

Evaluation indexes

\begin{tabular}{|c|c|c|c|}
\hline \multirow{2}{*}{$\begin{array}{l}\text { Coefficient of } \\
\text { coverage of } \\
\text { capital assets }\end{array}$} & \multirow{2}{*}{$\begin{array}{c}\text { Borrowed on } \\
\text { equity terms } \\
\text { coefficient }-K_{b e}\end{array}$} & \multicolumn{2}{|c|}{ Dynamics of indexes } \\
\hline & & $\begin{array}{l}\text { Borrowed on equity } \\
\text { terms coefficient }\end{array}$ & $\begin{array}{l}\text { Financial } \\
\text { leverage }\end{array}$ \\
\hline
\end{tabular}

\begin{tabular}{llll}
\hline 1. Minimum & $K_{c a} \geq 1$ & $K_{b e} \leq 1$ & $K_{b e}(t)=K_{b e}(0)-a t \quad F L(t)=F L(0)+a t$ \\
\hline 2. Middle & $K_{c a} \geq 1$ & $K_{b e} \geq 1$ & $K_{b e}(t)=K_{b e}(0)-a t \quad F L(t)=F L(0)-a t$ \\
\cline { 2 - 4 } & $K_{c a} \geq 1$ & $K_{b e} \leq 1$ & $K_{b e}(t)=K_{b e}(0)+a t \quad F L(t)=F L(0)-a t$ \\
\hline 3. High & $K_{c a} \geq 1$ & $K_{b e} \geq 1$ & $K_{b e}(t)=K_{b e}(0)+a t \quad F L(t)=F L(0)-a t$ \\
\cline { 2 - 4 } & $K_{c a}<1$ & $K_{b e} \leq 1$ & $K_{b e}(t)=K_{b e}(0)-a t \quad F L(t)=F L(0)+a t$ \\
\cline { 2 - 4 } & $K_{c a} \leq 1$ & $K_{b e} \geq 1$ & $K_{b e}(t)=K_{b e}(0)-a t \quad F L(t)=F L(0)+a t$ \\
\hline 4. Situation of appearance of financial risk & $K_{c a} \geq 1$ & $K_{b e} \leq 1$ & $K_{b e}(t)=K_{b e}(0)+a t \quad F L(t)=F L(0)+a t$ \\
\hline
\end{tabular}


Table 6. Determination of level of financial risk of enterprise, being at the maturity stage

\begin{tabular}{|c|c|}
\hline Level of financial risk & $\begin{array}{l}\text { Coefficient of } \\
\text { of capital a }\end{array}$ \\
\hline 1. Minimum & $K_{c a} \geq$ \\
\hline 2. Middle & $K_{c a} \geq$ \\
\hline 3. High & $K_{c a} \leq$ \\
\hline 4. Situation of appearance of financial risk & $K_{c a}<$ \\
\hline $\begin{array}{l}\text { Where 1) } N T(t)=N T(0)+a t ; 2) N T(t)=\Lambda \\
\text { thor's practical experience demonstrates } \\
\text { tests to discover financial risks, it is poss } \\
\text { Duran's technique (Romancevucha, Vor } \\
\text { The essence of the technique lies in the } \\
\text { level of risk to an enterprise in relevance } \\
\text { of indicatives of financial stability and } \\
\text { indicator expressed in scores according } \\
\text { sessment. Irrespective of the kinds of te } \\
\text { analyst for discovering financial risks o } \\
\text { forget, that these are instruments of short } \\
\text { and it is recommended to analyse the sta } \\
\text { management at an enterprise. }\end{array}$ & $\begin{array}{l}T(0)-a t . \\
\text { that by using } \\
\text { ble to employ } \\
\text { onova 2005). } \\
\text { attribution of } \\
\text { to actual level } \\
\text { ating of each } \\
\text { to expert as- } \\
\text { ts used by an } \\
\text { ne should not } \\
\text {-term analysis } \\
\text { te of strategic }\end{array}$ \\
\hline
\end{tabular}

\section{Techniques of drawing a map of risk of an enterprise}

In order to take into account and manage all risks of an enterprise, i.e. realize the concept of comprehensive system of risk management, it is necessary to draw a map of risks. Application of special methods for assessing separate kinds of risk does not allow to sum up all the profile of a risk of an enterprise. There are various ways of implementing a drawing of risk profile. (Barton et al. 2002; Order provided... 2006). The most popular are the techniques of drawing a matrix with an assessment according to scores, points or letters. In view of this goal an enterprise should have a scale of assessment developed: time of impact $\left(p_{t}\right)$, probability $\left(p_{i}\right)$, consequences (financial or some others) $\left(p_{f}\right)$. The scale is being developed with a different number of levels from 3 to $5-10$. The author's personal experience testifies to the fact, that it would be more prudent to use the scale for assessment of probability consequences and length of impact with the same number of levels. Assessment of levels of risk on score points $(R S)$ may be carried out by means of one of the following formula (Australian... 2006; Technique... 2006; Main... 2007; Pettere, Voronova 2003):

$$
\begin{aligned}
& R S=p_{i} \cdot p_{f}, \\
& R S=p_{i} \cdot\left(p_{f}+p_{t}\right),
\end{aligned}
$$

Evaluation indexes

Dynamics of indexes

Net rum Turnover of circulating assets

$N T(t)>N T(0)^{1)} \quad K_{a}(t)>K_{a}(0)$

$N T(t)>N T(0) \quad K_{a}(t)<K_{a}(0)$

$\begin{array}{lll}N T(t)<N T(0)^{2)} & K_{a}(t)>K_{a}(0)\end{array}$

$N T(t)<N T(0) \quad K_{a}(t)<K_{a}(0)$

$$
\begin{aligned}
& R S=p_{f} \cdot\left(p_{i}+p_{t}\right), \\
& R S=p_{i}+\max \left(p_{f} ; p_{t}\right) .
\end{aligned}
$$

Choice of a number of assessed parameters and the technique of total assessment of risk are determined by the field of production size of an enterprise and are ruled according to the Policy of enterprises in the field of risk management, which is developed supporting technical standards in the sphere of risk management. Along with risk level assessment any enterprise should have a risk scale developed: not allowed, not desirable, allowed under control, allowed at risk, etc.

For example, for five-level scale of assessment of probability and consequences a scale of risk level may be the following: 1-5 RS-Low; 6-12 RS-Medium; 13$25 R S$ - High Risk Level. Obtained assessment of risk level is depicted graphically in the form of a risk map. Risk profile should not be focussed exclusively on the risks subject to management in accordance with the laws (environment and safety), but include other risks affecting the activity of an enterprise and which should be responded to.

\section{Conclusions}

1. Organization of risk management at enterprises of non-financial sphere is carried out relying on tactical standards in the field of risk management. Finding out risk factors and its assessment is an important element of risk management. In order to find out and analyse different kinds of risk it is possible to use various methods.

2. While analyzing risk it is reasonable to use both traditional methods and also non-traditional - astrolinguistics which takes into account occurring of cyclical processes in the economy. Complex application of various methods allows to increase the quality and promptness of the obtained information about external environment and reduce entrepreneurial risk. 
3. To single out the reasons of financial risks it is reasonable to apply a wide range of techniques, including a system of tests, in which the financial ratios used are selected with a view to taking into account the peculiarities of financial risk development according to the stages of the life cycle of an enterprise. Duran's technique may be used for express analysis of financial risk.

4. Developing the policy of risk management one should determine a scale system aiming at assessing the profile of all risks and choose such a number of levels which will probably be suitable for assessment of as many risks as possible. Following the recommendations of tactical standards in the field of risk management allows to use unified techniques and diminish creation of the system of risk management.

\section{References}

Australian/New Zealand Standard AS/NZS 4360:2994 Risk Management. 2006. Available from Internet: <www. gio.com.au/gio/pdf_files/nfp_melb_cotronis_part_1.pdf $>$.

A Risk Management Standard. 2002. AIRMIC, ALARM, IRM:2002. Available from Internet: $<$ http://www.therrm. org/publications/docu-ments/ Risk_Management_Standad_030820.Pdf20>.

Barton, T.; Shenkir, W.; Walker, P. 2002. Making enterprise risk management pay off. Financial Times - Prentice Hall. $257 \mathrm{p}$.

Budjashkina, S. 2002. Uniqueness of personality and time, Mystery 3: 10-11 (in Latvian).

Doing Business in 2006 - Creating Jobs. Available from Internet: <http://www. doin gbusiness.org/ExploreEcono$\operatorname{mies} />$.

Economist Intelligence Unit. ViewsWitre. Country scorecard. 2007. Available from Internet: $<$ http://www.viewswire.com/index.asp?layout=VWCountryVW3\&region $\mathrm{id}=$ \&country_id=1680000168 $>$.

Guidance of risks: Possibility competitiveness improves in Central and Eastern Europe. Research of risks 2006. Marsh.
Available from Internet: <http://www.marsh.lv/aktuali/index.php> (in Latvian).

Independent Directors Have Key Role in Managing Risk. 2007. Available from Internet: <http://www.ey.com/global/ content.nsf/International/>. Media_-_Press_Release_-_Borard_Members_on_Risk

Jakovec, J. V. 1999. Cycles. Crises. Forecast. Moscow: Science (in Russian).

Komkova, J.; Voronova, I. I. 2003. Risk prevention and financial model in commercial activities, in The Economic Investigations Entrepreneurship. Vol 1. Riga: RTU, 63-71 (in Latvian).

Main trends of assessment of working environment risks. 2007. Available from Internet: <www.vdi.lv/admin/files/ info\%20materiaali/2.2.rus.pdf $>$ (in Russian).

Mougle, R. 1995. Cycles 45(May 3).

Order provided for introduction of the risk management process under the guidance of the European structural funds. 2006. Available from Internet: <www.esfondi.lv/upload/aktiesibu_akti/282_pielikumsdoc $>$ (in Latvian).

Pettere, G.; Voronova, I. 2003. Entrepreneurial risk and its management. Riga: Banking Institution of Higher Education. 186 p. (in Latvian).

Risk Management: Risk. Steady development. Synergetic. Moscow: Science, 2000, 20-124 (in Russian).

Romancevucha, J.; Voronova, I. 2005. Assessment of economic stability of enterprise. Riga: School of Business Administration (in Latvian).

Schumpeter, J. 1939. Business cycles. A theoretical, historical and statistical analysis of the capital progress. Vol. 1-11. N.L.

Technique "Order how to do financial and economic accounting to make decision about initiation of the procedures of obtaining the rights for concluding the contract about concession". 2007. The Ministry of Economy. Available from Internet: <www.em.gov.lv/em/images/modules/items/item file_12643_1.doc $>$ (in Latvian).

Zalozneva, J. 2007. Practical business astrology. Available from Internet: <htt://www. astrologic.ru/wtboard/4154. shtml $>$ (in Russian). 